\title{
Quantitation of the Pathways of Hepatic Glycogen Formation on Ingesting a Glucose Load
}

\author{
Inger Magnusson, Visvanathan Chandramouli, William C. Schumann, \\ Kozhikot Kumaran, John Wahren, and Bernard R. Landau \\ Department of Clinical Physiology, Karolinska Institute at Huddinge Hospital, Stockholm, Sweden; and \\ the Departments of Medicine and Biochemistry, Case Western Reserve University, Cleveland, Ohio 44106
}

\begin{abstract}
Diflunisal, 5-(2',4'-difluorophenyl)salicylic acid, excreted in urine as its glucuronide, was given to normal humans $(n=6)$ along with a glucose load specifically labeled with ${ }^{14} \mathrm{C}$. Glucuronide excreted by each subject was reduced to its glucoside and glucose from it degraded to yield the distribution of ${ }^{14} \mathrm{C}$ in its six carbons. Randomization of the ${ }^{14} \mathrm{C}$ from the specifically labeled glucose was taken as a measure of the extent to which glucose was deposited indirectly (i.e., glucose $\rightarrow$ lactate $\rightarrow$ glucose-6-P $\rightarrow$ glycogen), rather than directly (i.e., glucose $\rightarrow$ glucose-6-P $\rightarrow$ glycogen). The maximum contribution to glycogen formation by the direct pathway was estimated to be $65 \pm 1 \%$, on the assumption that glucuronide and glycogen are derived from the same hepatic pool of glucose-6-P in liver.

Evidence that supports that assumption was obtained by comparing the randomization of ${ }^{14} \mathrm{C}$ in the urinary glucuronide with that in glucose in blood from the hepatic vein of four of the subjects before and after they were given glucagon. Other evidence supporting the assumption was obtained by comparing in two subjects ${ }^{3} \mathrm{H} /{ }^{14} \mathrm{C}$ ratios in glucose from hepatic vein blood before and after glucagon administration with that in urinary glucuronide, having labeled the uridine diphosphate (UDP)glucose in their livers with ${ }^{14} \mathrm{C}$ by giving them $1-\left[{ }^{14} \mathrm{C}\right]$ galactose and their circulating glucose with ${ }^{3} \mathrm{H}$ by giving a $5-\left[{ }^{3} \mathrm{H}\right]-$ glucose-labeled load. It is concluded that glucuronide formation in humans can be used to trace glucose metabolism in the liver, and that in humans the indirect pathway of glucose metabolism is active.
\end{abstract}

\section{Introduction}

Contributions of different biochemical pathways to glucose metabolism in livers of animals in various physiological and pathological states have been estimated. This has been done by administering glucoses, specifically labeled with ${ }^{14} \mathrm{C}$, to the animals and determining the distribution of the label in either the carbons of glucose-6-P or of the glucose units of glycogen formed in their livers (1). Such tracings are not feasible in humans because, even with the maximum permissible quantity of label, a large amount of liver is required to yield sufficient label in glucose-6-P or glycogen for the tracings.

Address reprint requests to Dr. Wahren, Department of Clinical Physiology, Huddinge University Hospital, S-141 86 Stockholm, Sweden.

Presented in part at the Association of American Physicians' 1986 Annual Meeting. (1986. Clin. Res. 34:726a. Abstr.)

Received for publication 3 November 1986 and in revised form 25 March 1987.

J. Clin. Invest.

(c) The American Society for Clinical Investigation, Inc.

$0021-9738 / 87 / 12 / 1748 / 07 \quad \$ 2.00$

Volume 80, December 1987, 1748-1754
Uridine diphosphate (UDP)-glucose, formed from glucose-6-P, is the immediate precursor of the glucose unit in glycogen formation and of UDP-glucuronic acid, the immediate precursor in glucuronide formation. No rearrangement of carbon occurs in the reactions between glucose-6-P, glycogen, and glucuronide formation. Compounds that are excreted conjugated with glucuronic acid have been given to animals along with ${ }^{14} \mathrm{C}$-labeled substrates $(2,3)$ and the distributions of ${ }^{14} \mathrm{C}$ in glucuronic acid from the excreted glucuronides have then been used to trace the pathways followed by the carbons of the substrates. A number of drugs, when given to humans, are excreted in urine as glucuronides (4). This is a report on the use of one such drug, diflunisal, to sample in humans the UDP-glucose pool from which the glucuronide is formed (Fig. 1). Diflunisal, an aspirin-like compound, can safely be given in a gram quantity to a human. It is excreted in part as its ether glucuronide and the glucuronide is readily isolated from urine $(5,6)$.

To test the method we have given diflunisal to humans along with ${ }^{14} \mathrm{C}$-labeled glucose loads to estimate the pathways followed by the glucose carbons in their conversion to glycogen, assuming that glucuronide and glycogen are formed in liver from a common pool of UDP-glucose or from two pools of UDP-glucose, but from a common pool of glucose-6-P. There is considerable evidence that in animals (7-14), a large portion of the glucose carbons of a load is deposited in glycogen only indirectly, i.e., after cleavage of the glucose to a three-carbon compound, lactate, or its metabolic equivalent.

The ${ }^{14} \mathrm{C}$-labeled ether glucuronide of diflunisal excreted by each subject was reduced to its corresponding glucoside. The glucoside was hydrolyzed and the glucose that formed was degraded to yield the distribution of ${ }^{14} \mathrm{C}$ in the carbons of the glucose. Since glucuronides can be formed in tissues other than liver (4) and there may be more than one pool of glucose-6-P in liver, the assumption that the glucuronide of diflunisal is formed in human liver and from the same glucose-6-P pool as the glucose units of glycogen was tested. This was done in two ways. In one way, after the administration of the ${ }^{14} \mathrm{C}$-labeled glucose, glucose in blood drawn from the subject's hepatic vein during glucagon administration was degraded and the distribution of ${ }^{14} \mathrm{C}$ in it compared with that in the glucose from the glucuronide. In the other way, ${ }^{14} \mathrm{C}$-labeled galactose was administered along with a ${ }^{3} \mathrm{H}$-labeled glucose load to preferentially label the hepatic UDP-glucose pool with ${ }^{14} \mathrm{C}$ relative to ${ }^{3} \mathrm{H}$. Then the ${ }^{3} \mathrm{H} /{ }^{14} \mathrm{C}$ ratio in the glucuronide was compared with that in the blood glucose.

\section{Methods}

Subjects. Eight healthy volunteers were studied, three men and five women, aged 21 to $30 \mathrm{yr}$, weighing 52 to $84 \mathrm{~kg}$, and each within $15 \%$ of ideal body weight. They consumed a weight-maintaining diet, containing at least $200 \mathrm{~g}$ of carbohydrate, for at least $3 \mathrm{~d}$ before ingesting 


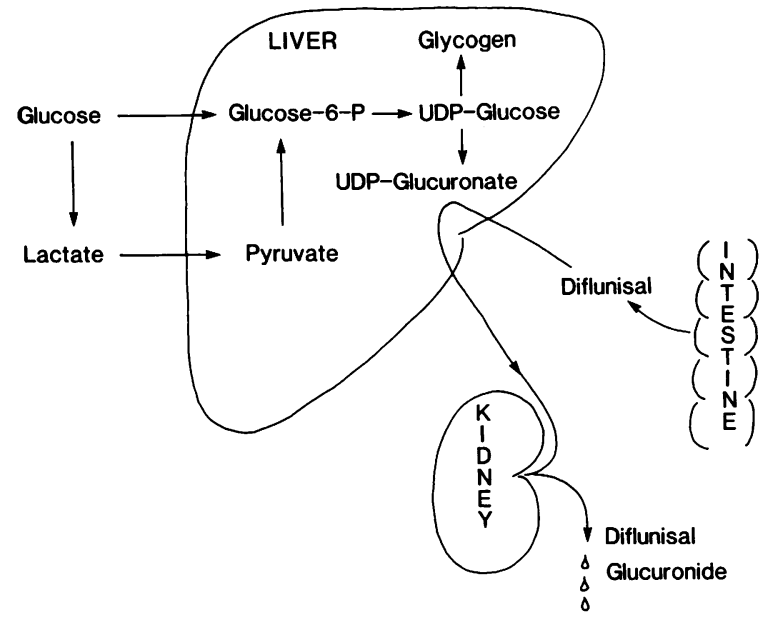

Figure 1. Pathway of formation of diflunisal glucuronide in liver and its urinary excretion. Also illustrated are the two pathways of glycogen formation, the direct in which glucose carbons go to glycogen via glucose-6-P without cleavage and the indirect in which cleavage is to three carbon intermediates. It is assumed glucuronide and glycogen formation is from a common pool of UDP-glucose.

the glucose load. None were taking any medication. The experimental protocol was approved by the Human Investigation Committees at Huddinge University Hospital and at University Hospitals of Cleveland. Informed consent was obtained from each subject.

Procedure. After an overnight fast, each of the subjects ingested $1 \mathrm{~g}$ glucose/ $\mathrm{kg}$ body wt as a $30-46 \%$ aqueous solution over a 5-min period. $30 \mathrm{~min}$ before ingesting the glucose, each subject swallowed $1 \mathrm{~g}$ of diflunisal. For five subjects the glucose load contained $20 \mu \mathrm{Ci}$ of 6$\left[{ }^{14} \mathrm{C}\right]$ glucose. For the sixth the load was labeled with $20 \mu \mathrm{Ci}$ of $5-\left[{ }^{14} \mathrm{C}\right]-$ glucose. For the seventh the load contained $100 \mu \mathrm{Ci}$ of $5-\left[{ }^{3} \mathrm{H}\right]$ glucose with $20 \mu \mathrm{Ci}$ of $1-\left[{ }^{14} \mathrm{C}\right]$ galactose in $5 \mathrm{~g}$ of galactose. For the eighth subject, the load was labeled only with $5-\left[{ }^{3} \mathrm{H}\right]$ glucose and $1-\left[{ }^{14} \mathrm{C}\right]-$ galactose was infused intravenously during the $3.5 \mathrm{~h}$ that followed the beginning of the ingestion of glucose.

A No. 7 or 8 Cournand catheter was inserted percutaneously into a femoral vein of each of three subjects given $6-\left[{ }^{14} \mathrm{C}\right]$ glucose, the one given $5-\left[{ }^{14} \mathrm{C}\right]$ glucose and the two given $1-\left[{ }^{14} \mathrm{C}\right]$ galactose and $5-\left[{ }^{3} \mathrm{H}\right]-$ glucose. The catheter was manipulated under fluoroscopy into a rightsided hepatic vein and kept patent with isotonic saline. $3 \mathrm{~h}$ after the ingestion of glucose, $\left(4.5 \mathrm{~h}\right.$ for the subject given $5-\left[{ }^{14} \mathrm{C}\right]$ glucose $)$, glucagon was infused through a peripheral vein at the rate of $36 \mathrm{ng} / \mathrm{kg}$ body wt per min (15). $50 \mathrm{ml}$ of blood was drawn from the hepatic vein each hour and $2 \mathrm{ml}$ on the half-hour until just before the administration of glucagon; $50 \mathrm{ml}$ was drawn 15 and $30 \mathrm{~min}$ after the beginning of the infusion of glucagon. In the two subjects who were not catheterized and given glucagon, $50-\mathrm{ml}$ blood samples were also drawn hourly from an antecubital vein. In the subjects given 1- $\left[{ }^{14} \mathrm{C}\right]$ galactose and 5- $\left[{ }^{3} \mathrm{H}\right]-$ glucose, $25-\mathrm{ml}$ blood samples were drawn half-hourly until the beginning of glucagon administration and then 15 and 30 min after that.

Urine was collected from the time of glucose ingestion until glucagon was administered or until $30 \mathrm{~min}$ after beginning glucagon. In the two subjects not given glucagon it was collected for $3 \mathrm{~h}$ after glucose ingestion.

Materials. 6- $\left[{ }^{14} \mathrm{C}\right]$ Glucose and 1-[ $\left.{ }^{14} \mathrm{C}\right]$ galactose were purchased from Research Products International Corp., Mount Prospect, IL and 5- $\left[{ }^{3} \mathrm{H}\right]$ glucose from New England Nuclear, Boston, MA. We prepared $5-\left[{ }^{14} \mathrm{C}\right]$ glucose (1). Purities of the glucoses were indicated, beyond the evidence provided by the commercial manufacturers, by demonstrating that each one gave a single peak of radioactivity with the mobility of glucose on high pressure liquid chromatography (HPLC) using an Aminex HPX-87P carbohydrate analysis column (Bio-Rad Laboratories, Richmond, CA) with water at $80^{\circ} \mathrm{C}$ as solvent (16). Dolobid (diflunisal), in $500 \mathrm{mg}$ tablets, was a gift from Merck Sharp \& Dohme, West Point, PA.

Analyses. Glucose concentrations in the blood samples were determined enzymatically (17). To the remainder of each of the $50 \mathrm{ml}$ and $25 \mathrm{ml}$ blood samples was added three times its volume of $1.5 \mathrm{M}$ perchloric acid. The precipitate was removed by centrifugation. The supernatant was neutralized with $\mathrm{KOH}$ and cooled, and the resulting precipitate of potassium perchlorate was also removed by centrifugation. The supernatant was deionized by passage through a mixed bed ion exchange resin (Amberlite MB-3; Mallinkrodt, Paris, KY). The effluent was evaporated to a small volume. The solution usually became cloudy and because of this, $\mathrm{Ba}(\mathrm{OH}) 2$ and $\mathrm{ZnSO} 4$ were added (18). The suspension was centrifuged and the resulting supernatant was also passed through the mixed bed resin and evaporated to dryness. When $5-\left[{ }^{3} \mathrm{H}\right]$ glucose and $1-\left[{ }^{14} \mathrm{C}\right]$ galactose were given the ${ }^{3} \mathrm{H} /{ }^{14} \mathrm{C}$ ratio in the residue was determined by oxidizing it to ${ }^{14} \mathrm{CO}_{2}$ and ${ }^{3} \mathrm{H}_{2} \mathrm{O}$ using a TriCarb sample oxidizer (306; Packard Instrument Co., Inc., Downers Grove, IL), and assaying for radioactivity in a liquid scintillation spectrometer. The residue could have contained both glucose and galactose. However, in keeping with the rapid uptake of galactose by liver, when portions of the residues were incubated with galactose oxidase and then passed through the mixed bed ion exchanger, the ratios in the effluents were unchanged. When ${ }^{14} \mathrm{C}$-labeled galactose is treated in this way, $95-99 \%$ of its ${ }^{14} \mathrm{C}$ is retained on the column. Thus, the ratios determined are essentially those in glucose.

When the load was labeled with $\left[{ }^{14} \mathrm{C}\right]$ glucose, the residue was applied to Whatman 3MM paper (Whatman Inc., Clifton, NJ) and chromatographed using a butanol/acetic acid/water (4:1:5 vol/vol) system (19). Glucose, the position of which was established by guide spots, was eluted from the paper and further purified by HPLC using the Aminex HPX-87P column. Most of the glucose (the quantity isolated ranged from 12 to $29 \mathrm{mg}$ and had 3,600 to $9,000 \mathrm{dpm}$ ) was degraded to yield each of its carbons as $\mathrm{CO}_{2}$ and the $\mathrm{CO}_{2}$ 's were analyzed for ${ }^{14} \mathrm{C}(1,10)$. A small portion was combusted to $\mathrm{CO}_{2}$ and that $\mathrm{CO}_{2}$ also was assayed for ${ }^{14} \mathrm{C}$. In the table to be presented, the sum of the ${ }^{14} \mathrm{C}$ specific activities of the six carbons of each glucose, determined by degradation, multiplied by 100 and divided by the specific activity of the glucose determined by the combustion, is recorded as percent ${ }^{14} \mathrm{C}$ recovery. This serves as a measure of the purity of each glucose and the adequacy of its degradation.

Each urine was adjusted to $\mathrm{pH} 4.5$ to prevent breakdown of the glucuronide (6). It was frozen pending continuous extraction. It was acidified to $\mathrm{pH} 2$ with $\mathrm{H}_{2} \mathrm{SO}_{4}$ and extracted with diethyl ether for $48 \mathrm{~h}$ $(5,6)$. The ether extract, which now contained the diflunisal ether glucuronide, was washed with a small volume of water, dried over magnesium sulphate, and evaporated. The residue was dissolved in dimethoxyethane and, while stirring, diborane-tetrahydrofuran complex was added in excess (20). The vessel was capped with a drying tube of $\mathrm{CaSO}_{4}$ and the mixture was stirred at room temperature overnight. Water was then added to decompose the excess diborane. The mixture was acidified, methanol was added, and the resulting solution was evaporated to dryness. Solution in methanol and evaporation to dryness was done twice more to remove boric acid as methyl borate. The residue, dissolved in acetate buffer, $\mathrm{pH} 5.0$, with beta-glucosidase added (6), was incubated at $37^{\circ} \mathrm{C}$ overnight with shaking. When the hydrolysis was complete, as evidenced by cessation of the increase in glucose content, $\mathrm{Ba}(\mathrm{OH})_{2}$ and $\mathrm{ZnSO}_{4}$ were added. The supernatant was deionized by passage through a column of the mixed bed ion exchange resin. The effluent was concentrated and the glucose in it isolated, using HPLC and degraded as for glucose from blood. From 15 to $25 \mathrm{mg}$ of glucose (1,400 to $1,700 \mathrm{dpm})$ was isolated from a urine collection of 3-5 h. The yields of glucose from the urinary glucuronide were $60-80 \%$ of the theoretical yield.

For one subject given $5-\left[{ }^{3} \mathrm{H}\right]$ glucose and $1-\left[{ }^{14} \mathrm{C}\right]$ galactose, we determined the ratio of ${ }^{3} \mathrm{H} /{ }^{14} \mathrm{C}$ in the glucose from the glucuronide. The residue from the diethyl ether extraction of the urine of the other subject was chromatographed by HPLC using a reverse phase octadecylsilane column (C 18 column; Alltech Associates, Inc., Deerfield, IL) 
and linear gradient elution with solvents of methanol and dilute acetic acid (6). The ether glucuronide peak was collected and evaporated to dryness and an aliquot of the residue was assayed for ${ }^{14} \mathrm{C}$ and ${ }^{3} \mathrm{H}$. The remainder of the residue was incubated in the acetate buffer with beta-glucuronidase. The supernatant, obtained after the addition of $\mathrm{Ba}(\mathrm{OH})_{2}$ and $\mathrm{ZnSO}_{4}$, was lyophilized to dryness and the resulting residue, dissolved in sodium hydroxide, was applied to a Bio-Rad AG1-X8 column in the acetate form and eluted with acetic acid (21). The fraction containing glucuronic acid was identified using carbazole (22) and evaporated to dryness. The glucuronic acid was further purified by applying it to a Aminex HPX 87H organic acid analysis column and eluting it under high pressure with water acidified to $\mathrm{pH} 2.5$ with $\mathrm{H}_{2} \mathrm{SO}_{4}$. The fraction containing the glucuronic acid was evaporated and oxidized to $\mathrm{CO}_{2}$, which was assayed for ${ }^{14} \mathrm{C}$ activity, and to $\mathrm{H}_{2} \mathrm{O}$, which was assayed for ${ }^{3} \mathrm{H}$ activity.

\section{Results}

The means with standard errors of the percentage distributions of ${ }^{14} \mathrm{C}$ in the carbons of the glucoses from the glucuronides from the five subjects given $6-\left[{ }^{14} \mathrm{C}\right]$ glucose are illustrated in Fig. 2. Of the ${ }^{14} \mathrm{C}$ in the glucoses, $72 \pm 1 \%$ was in carbon 6 ; there was 5 to $6 \%$ in carbons 2 and 5 , more in carbon 1 than 2 and less in carbons 3 and 4 than in the other carbons.

Fig. 3 shows the mean percentages with standard errors of ${ }^{14} \mathrm{C}$ in the carbons of the blood glucoses before and during glucagon administration and in the glucoses from the glucuronides of the three subjects whose hepatic veins were catheterized and who were given $6-\left[{ }^{14} \mathrm{C}\right]$ glucose. Randomization of ${ }^{14} \mathrm{C}$, as evidenced by the proportion of ${ }^{14} \mathrm{C}$ in carbon 6 , was greater in the glucose from the blood obtained during than before glucagon administration, and it was also greater in the glucose from the glucuronide than in the glucose from the blood obtained during glucagon administration. This was also the case when $5-\left[{ }^{14} \mathrm{C}\right]$ glucose was fed (Table I). Within $15 \mathrm{~min}$ after the beginning of glucagon administration, blood glucose concentrations increased an average of $50 \%$ (range 14 to $108 \%)$.

The distributions of ${ }^{14} \mathrm{C}$ in the glucose from each subject given ${ }^{14} \mathrm{C}$-labeled glucose are presented in Table I. Glucose

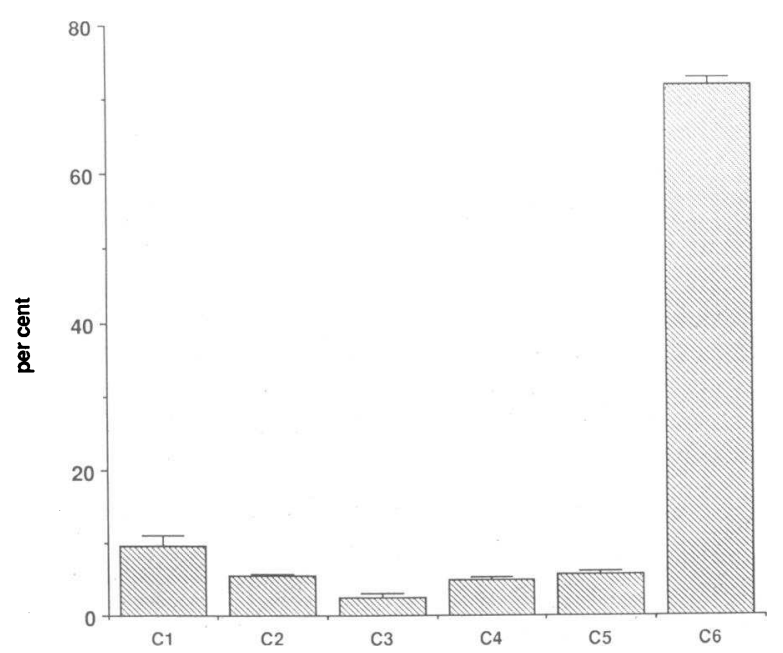

Figure 2. Distribution of ${ }^{14} \mathrm{C}$ in the six carbons of the glucose from the glucuronides excreted by the five subjects given $6-\left[{ }^{14} \mathrm{C}\right]$ glucose. The heights of the columns depict the percentages in each carbon with the lengths of the bars depicting \pm the standard errors.

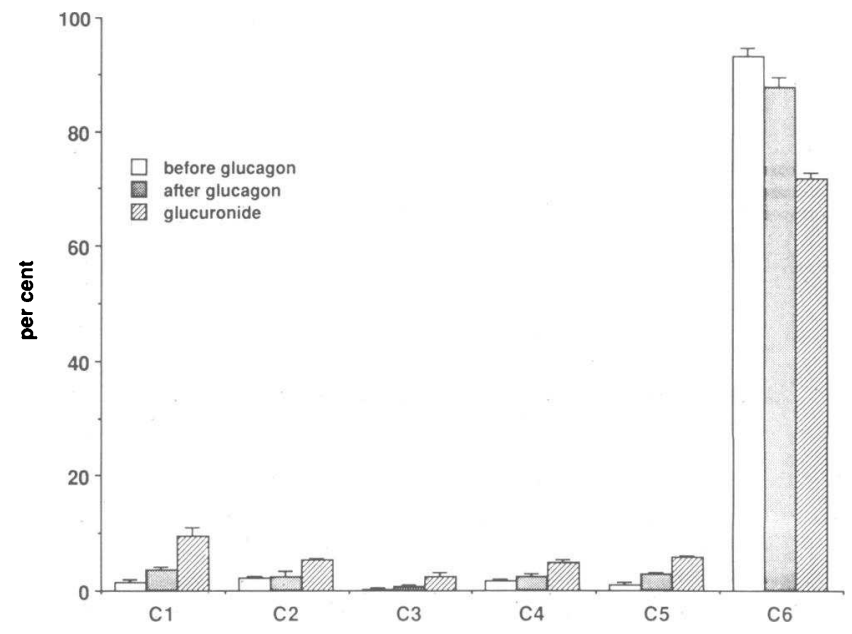

Figure 3. Distribution of ${ }^{14} \mathrm{C}$ in the six carbons of glucose in the blood before and during glucagon administration and in the glucoses from the urinary glucuronide from the three subjects given $6-\left[{ }^{14} \mathrm{C}\right]-$ glucose in whom these determinations were made. Bars depict mean \pm the standard errors.

from blood drawn from subjects 1,2 , and 6 just before glucagon administration were degraded and glucose from blood collected 1,2 , and $3 \mathrm{~h}$ after glucose ingestion by subject 3 were combined and degraded. Glucose from blood drawn during glucagon administration from each of these subjects was also degraded.

The ratios of ${ }^{3} \mathrm{H} /{ }^{14} \mathrm{C}$ in the blood of the two subjects and in the glucuronides they excreted after the administration of 5$\left[{ }^{3} \mathrm{H}\right]$ glucose and $1-\left[{ }^{14} \mathrm{C}\right]$ galactose are illustrated in Fig. 4. Until glucagon was given, the ratios in the blood were higher than the ${ }^{3} \mathrm{H} /{ }^{14} \mathrm{C}$ ratio of five in the administered sugars. The ratios in the bloods then fell to low values, but the ${ }^{3} \mathrm{H} /{ }^{14} \mathrm{C}$ ratio in the urinary glucuronide from each subject was still lower. ${ }^{1}$

\section{Discussion}

There is no randomization of carbon between glucose-6-P and glycogen. Diflunisal glucuronide samples a hepatic UDP-glucose pool and hence, in essence, the carbons of its precursor glucose-6-P and, if glycogen is formed from that pool, also the carbons of the glucose unit of the glycogen. Besides being readily isolated from urine, the use of the glucuronide has the advantage that the tracing of glucose's metabolism is independent of glycogen formation. A disadvantage is that, while a gram of diflunisal can be taken by an adult, only a small

1. From the urine of the second subject who received the $1-\left[{ }^{14} \mathrm{C}\right]-$ galactose intravenously, glucuronic acid was cleaved from the diflunisal glucuronide and purified. The ${ }^{3} \mathrm{H} /{ }^{14} \mathrm{C}$ ratios in the glucuronide and glucuronic acid were determined (see Methods). They were the same. We went through an extensive purification of the glucuronic acid because of the possibility of an undetected contaminant in the glucuronide that affected the ratio. We chose to determine the ${ }^{3} \mathrm{H} /{ }^{14} \mathrm{C}$ ratio in the glucuronide rather than in glucose, as done in the first subject, to eliminate the possibility of a loss of ${ }^{3} \mathrm{H}$ during conversion of the glucuronide to glucose. Subject 2's fasting plasma glucose concentration was $5.4 \mathrm{mM}$. It rose to $8.5 \mathrm{mM}$, then declined at $150 \mathrm{~min}$ to $4.5 \mathrm{mM}$, but then returned toward normal by $3 \mathrm{~h}$. The fall in ${ }^{3} \mathrm{H} /{ }^{14} \mathrm{C}$ ratio in the glucose during this period may be attributed to the release of endogenous glucagon, a fall, accelerated on glucagon administration. 


\begin{tabular}{|c|c|c|c|c|c|c|c|c|c|}
\hline \multirow[b]{2}{*}{ Subject } & \multirow{2}{*}{$\begin{array}{l}\text { Labeled } \\
\text { glucose }\end{array}$} & \multirow[b]{2}{*}{ Source } & \multicolumn{6}{|c|}{$\%{ }^{14} \mathrm{C}$ in carbon } & \multirow[b]{2}{*}{${ }^{14} \mathrm{C}$ recovery } \\
\hline & & & 1 & 2 & 3 & 4 & 5 & 6 & \\
\hline & & $h$ & & & & & & & $\%$ \\
\hline \multirow[t]{3}{*}{1} & $6-{ }^{14} \mathrm{C}$ & Urine $0-3$ & 15.2 & 4.9 & 2.0 & 3.7 & 4.7 & 70.2 & 103.7 \\
\hline & & Blood 3 & 1.6 & 2.2 & 0.3 & 2.1 & 1.0 & 92.9 & 89.9 \\
\hline & & Blood 3.25* & 3.2 & 3.0 & 0.6 & 1.6 & 2.2 & 89.6 & 92.6 \\
\hline \multirow[t]{3}{*}{2} & ${ }^{6-}{ }^{14} \mathrm{C}$ & Urine $0-3$ & 8.3 & 5.8 & 1.5 & 6.3 & 5.1 & 73.0 & 93.8 \\
\hline & & Blood 3 & 2.4 & 2.3 & 0.5 & 1.8 & 1.8 & 91.2 & 90.6 \\
\hline & & Blood 3.25* & 3.4 & 0.6 & 0.8 & 2.4 & 3.2 & 89.6 & 94.5 \\
\hline \multirow[t]{3}{*}{3} & $6-{ }^{14} \mathrm{C}$ & Urine $0-3.5$ & 8.6 & 5.5 & 4.9 & 5.7 & 6.0 & 69.4 & 96.8 \\
\hline & & Blood 1-3 & 0.5 & 2.2 & 0.1 & 1.1 & 0.2 & 96.0 & 92.7 \\
\hline & & Blood 3.5* & 4.6 & 3.6 & 0.8 & 3.4 & 3.1 & 84.4 & 96.5 \\
\hline 4 & ${ }^{6-}{ }^{14} \mathrm{C}$ & Urine $0-3$ & 8.8 & 6.2 & 2.0 & 3.7 & 7.1 & 72.1 & 92.3 \\
\hline 5 & ${ }^{6-14} \mathrm{C}$ & Urine $0-3$ & 7.3 & 4.7 & 1.9 & 4.8 & 6.2 & 75.0 & 90.0 \\
\hline \multirow[t]{3}{*}{6} & $5-{ }^{14} \mathrm{C}$ & Urine $0-5$ & 3.2 & 6.6 & 4.6 & 6.8 & 68.9 & 10.0 & 99.6 \\
\hline & & Blood 4.5 & 1.5 & 2.4 & 2.5 & 3.0 & 86.7 & 3.9 & 91.2 \\
\hline & & Blood 4.75* & 1.3 & 3.2 & 2.4 & 4.4 & 84.6 & 4.2 & 101.7 \\
\hline
\end{tabular}

* After glucagon.

portion $(\sim 5-10 \%)$ is excreted during the $3 \mathrm{~h}$ following its ingestion $(5,6)$. Furthermore, only a portion is excreted as its ether glucuronide, on the average only about one-half. The other major metabolite is the diflunisal ester glucuronide; this can be hydrolyzed during reduction with borane giving glucuronic acid, which on reduction would yield sorbitol rather than glucose (20). It is assumed that diflunisal does not alter the pathways being traced.

The ${ }^{14} \mathrm{C}$-labeled ether glucuronide we isolated is that formed from the time of ${ }^{14} \mathrm{C}$ and glucose ingestion. Therefore, the distributions in the glucoses from the glucuronides are not those at steady state. However, steady state was essentially achieved within $1 \mathrm{~h}$ after giving specifically labeled glucose

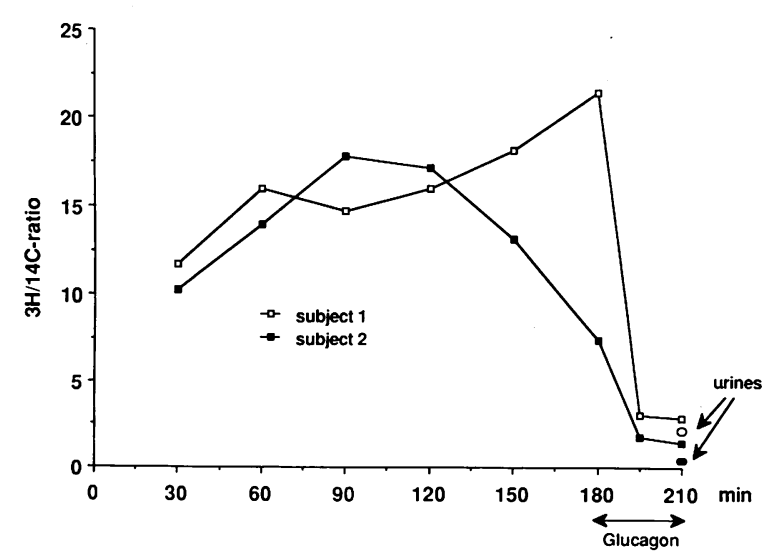

Figure 4. Ratios of ${ }^{3} \mathrm{H}$ to ${ }^{14} \mathrm{C}$ with time in blood from the two subjects given $1-\left[{ }^{14} \mathrm{C}\right]$ galactose and $5-\left[{ }^{3} \mathrm{H}\right]$ glucose in a glucose load before and during glucagon infusion, and the ${ }^{3} \mathrm{H}$ to ${ }^{14} \mathrm{C}$ ratios in the glucuronides they excreted during the $210 \mathrm{~min}$. loads to rats, as measured by incorporations into glycogen (8). The quantity of ${ }^{14} \mathrm{C}$ we gave did not allow for serial collections of urine with sufficient ${ }^{14} \mathrm{C}$ in the glucuronide in each collection for adequate degradation.

The distributions in Table I are similar to those we observed on administering $6-\left[{ }^{14} \mathrm{C}\right]$ glucose in glucose loads to rats (10). The extent of randomization is also similar to that observed by Shulman et al. (13), but less than that found by Newgard et al. (9) giving rats carbon one labeled glucose loads. There is evidence that in the rat the contributions of the pathways are functions of portal glucose concentrations (9).

The contributions of the pathways can be calculated from percentages in Fig. $2(9,10)$, assuming glycogen is derived from the same hepatic pool of glucose-6-P as the glucuronide. In the incorporation of ${ }^{14} \mathrm{C}$ into the glucose units of glycogen from 3-[ $\left[{ }^{14} \mathrm{C}\right]$ lactate formed from $6-\left[{ }^{14} \mathrm{C}\right]$ glucose, carbon 2 should have $\sim 80 \%$ as much ${ }^{14} \mathrm{C}$ as carbon 1 and carbon 5 $\sim 80 \%$ as much as in carbon $6(10,23,24)$. If there is complete equilibration of the triose phosphates, incorporation from the lactate should be into carbons $1,2,5$, and 6 with $\mathrm{C}-2=\mathrm{C}-5$ and $\mathrm{C}-1=\mathrm{C}-6$. The finding of similar incorporations into carbons 2 and 5 indicates this was the case. The maximum direct pathway contribution is then $65 \pm 1 \%$ (incorporation into carbon 6 less that incorporated via the indirect pathway [C-5/0.8]). The estimate of an indirect pathway contribution of $35 \%$ is a minimum estimate to the extent that dilution occurred by ${ }^{12} \mathrm{C}$ of ${ }^{14} \mathrm{C}$, whether by exchange reactions or entrance of glycogenic compounds into the pathway and to the extent steady state was not achieved.

The best estimate of the dilution of the labeled carbons of lactate in the Kreb's cycle during their conversion to glycogen appears to be about twofold. The extent of the direct and indirect pathway contributions would then be similar. However, the estimate of a twofold dilution is from studies in the 
rat $(13,25)$. Radziuk $(15,26)$, from measurements of incorporations of ${ }^{14} \mathrm{C}$ from $1-\left[{ }^{14} \mathrm{C}\right]$ glucose and ${ }^{14} \mathrm{CO}_{2}$ and glucose turnover using $3-\left[{ }^{3} \mathrm{H}\right]$ glucose, with mobilization of liver glycogen using glucagon, has concluded that in man given a glucose load, the amount of glycogen produced through new synthesis from precursors at the pyruvate level, is at least the same as that made by direct uptake of glucose. ${ }^{2}$ Ferrannini et al. (27) and Firth et al. (28) have reported that a portion of ingested glucose reaches the systemic circulation via the indirect pathway, but the method they used does not allow measurement of the extent of conversion of glucose to glycogen via this pathway.

Dilution of label between glucose and lactate and between oxaloacetate and the triose phosphates would lead to a further underestimation of the indirect pathway contribution. Dilution of label by exchange reactions and/or by precursors of glycogen entering via the direct pathway would result in that pathway's contribution being underestimated. There is evidence, again in the rat, for some dilution of label between glucose and lactate (11) and for glycogen synthesis from glycerol during the uptake of a glucose load $(13,29)$. Liver degrades and synthesizes glycoproteins and glycolipids, and the carbohydrate moieties of these compounds, among others, could participate in dilution of label within the direct pathway.

Incorporation into carbon 1 (Fig. 2) is somewhat greater than would occur via $3-\left[{ }^{14} \mathrm{C}\right]$ lactate $(23)$. This means that a small amount of randomization occurred through futile cycling at the fructose phosphate level, again agreeing with studies in rats (10). The percentage of ${ }^{14} \mathrm{C}$ in carbon 4 is greater than expected from incorporation via lactate (23) and this we believe is an artifact arising during degradation.

Estimation of the pathway contributions from the distribution obtained on administering $5-\left[{ }^{14} \mathrm{C}\right]$ glucose (Table I) is similar to that on giving $6-\left[{ }^{14} \mathrm{C}\right]$ glucose. The indirect pathway contribution to the incorporation into carbon 5 is estimated from the incorporation into carbon $6(\mathrm{C}-6 / 0.8)$. The larger percentage in carbon 6 than 1 suggests that in the subject there was incomplete isotopic equilibration at the triose phosphate level (23).

The present study does not allow conclusions with regard to the quantitative aspects of glucose disposal after the oral load. The results indicate the proportion of the glycogen formed after a glucose load synthesized via the direct and indirect pathways. However, the total amount of liver glycogen deposited cannot be estimated and therefore the present findings are not comparable to those obtained previously in humans using catheter technique. The latter reports indicate

2. Estimates of the direct pathway contribution have also been made from the incorporation of ${ }^{3} \mathrm{H}$ from ${ }^{3} \mathrm{H}_{2} \mathrm{O}$ into the glucose units of glycogen in rats (12) and from the specific activity of the glucose units of glycogen compared to the specific activity of the glucose administered or in the portal circulation when carbon labeled glucoses were administered $(8,10,13,14)$. The specific activity of the glucose units of glycogen have been one-quarter to one-half those of the glucose, giving a value for the direct pathway contribution of $25-50 \%$. In this study, the specific activities of the glucoses isolated from the glucuronides were about one-fifth of those of the glucoses isolated from the blood. While further quantitation is not possible because diflunisal was given before $\left[{ }^{14} \mathrm{C}\right]$ glucose, apparently the specific activity of the UDP-glucose from which the glucuronide was derived was much less than that of the circulating glucose. that between 20 and $40 \%$ of an oral load is taken up by the liver $(27,30)$ and presumably used for glycogen synthesis. If $25 \%$ or more of $20 \mathrm{~g}$ were to be synthesized from lactate and other three-carbon compounds this would require a flux of glucose precursors that has not been observed in humans $(30$, 31). Thus, the nature of these precursors and their site of formation remains to be determined. Irrespective of these considerations, the current findings demonstrate that the indirect pathway for glycogen formation is operative in humans.

It is difficult to conceive of any organ other than liver, except possibly kidney, where glucuronidation could have occurred to yield a distribution reflecting the gluconeogenic process. Pang and Gillette (32) found no evidence for extrahepatic metabolism of acetaminophen in rats whose livers were excluded from the circulation. Acetaminophen is converted by rat kidney to the glucuronide (33), but studies indicate this conversion is quantitatively small and that this is also so in man $(34,35)$. Two findings of ours support the view that the glucuronidation of the diflunisal took place primarily, if not completely, in liver and that the glucuronic acid moiety and glucose units of glycogen derived from the same pool of glucose-6-P.

Degradation of glucose in blood after beginning the administration of glucagon gives the distribution in a mixture of the glucose in the blood before glucagon administration and that released from the liver during its administration. Therefore, the actual distribution of ${ }^{14} \mathrm{C}$ in the glucose unit of glycogen cannot be obtained from the data in Fig. 3. However, the randomization in the glucose units of glycogen must have been more than that in the blood glucose during glucagon administration, since the percentages in carbon 1 through 5 increased with its administration. That the randomization in the urinary glucuronide is more than in the blood glucose after the beginning of glucagon administration and that the pattern of incorporation into the individual carbons is similar is then in accord with the assumption that the glucuronide was formed from the glucose-6-P pool from which glycogen was formed. The increased randomization following glucagon administration is in itself an indication that some liver glycogen was formed from glucose indirectly.

The results obtained by administering $1-\left[{ }^{14} \mathrm{C}\right]$ galactose and 5- $\left[{ }^{3} \mathrm{H}\right]$ glucose (Fig. 4) provide the other evidence for glucuronidation occurring in liver. Since galactose is primarily and readily utilized by liver and enters the metabolic scheme at the level of UDP-glucose, in the presence of a glucose load its carbons should be extensively incorporated into liver glycogen. Labeling of glycogen with ${ }^{3} \mathrm{H}$ from $5-\left[{ }^{3} \mathrm{H}\right]$ glucose would be expected to be less; indeed, via the indirect pathway, the ${ }^{3} \mathrm{H}$ would be lost to water in the formation of the glycogen. In accordance with this, the blood glucose before glucagon administration had a much higher ${ }^{3} \mathrm{H} /{ }^{14} \mathrm{C}$ ratio than during glucagon administration. This must mean that, as expected, the glucose units of glycogen had a lower ${ }^{3} \mathrm{H} /{ }^{14} \mathrm{C}$ ratio than found in blood during glucagon administration. That the urinary glucuronide had a very low ratio is then further evidence that the glucuronide reflects the ratio in glycogen.

Recently, Hellerstein et al. (36) reported a study in which they infused acetaminophen and $1-\left[{ }^{3} \mathrm{H}, \mathrm{U}-{ }^{14} \mathrm{C}\right]$ glucose into rats, gave glucose loads, and then isolated liver glycogen and urinary acetaminophen glucuronide. Because of differences in the patterns of labeling in glycogen and the glucuronide, they concluded that glycogen must be formed from a different pool 
of UDP-glucose than the glucuronide. This would then also necessitate two pools of glucose-6-P. What they found was that the ${ }^{3} \mathrm{H} /{ }^{14} \mathrm{C}$ ratio in the glucuronide was less than that of the glycogen when the glucose load was begun. Over the next several hours, as glycogen deposition continued, the ratios approached each other. ${ }^{14} \mathrm{C}$ specific activity of the glucuronide was initially higher than that of the glycogen, but with time they became the same, and with time the ${ }^{3} \mathrm{H}$ specific activities also approached each other, but more slowly.

We believe that the observations of Hellerstein et al. (36) actually indicate the presence of a single pool of glucose-6-P and not two pools. With two pools the differences would not be expected to decrease or disappear with increasing glycogen deposition. We believe that the differing patterns they observed are due to $(a)$ the labeling of the glucuronide in the rat before giving the glucose loads, $(b)$ giving loads that were unlabeled so that the circulating glucose specific activities declined, $(c)$ expressing for comparisons the radioactivity yields in glycogen and the glucuronide relative to the circulating glucose specific activities at the time of killing the rat and of urine collection, and $(d)$ measuring radioactivity in glucuronides collected from $30 \mathrm{~min}$ to $2 \mathrm{~h}$ and in liver glycogen from the beginning of deposition to the killing of the rat. Other contributions to the differences they observed, although likely to be minor, are the lag time in the enterohepatic circulation of the glucuronide (37) and possible slowly equilibrating pools of glucuronide in tissues in the rat (38). ${ }^{3}$

While we have used our approach to trace the fate of a glucose load, it would seem applicable to more general tracings of the pathways of carbohydrate metabolism in humans.

\section{Acknowledgments}

This work was supported by grant AM-14507 from the National Institutes of Health, by grants from the Lee Fund of University Hospitals of Cleveland and the Diabetes Association of Greater Cleveland, and by a grant from the Swedish Medical Research Council (No. 3108). Dr. Landau is the recipient of a John F. Fogarty Senior International Fellowship.

3. The ${ }^{3} \mathrm{H} /{ }^{14} \mathrm{C}$ ratio in the glucuronide was initially 0.36 and during glycogen deposition gradually approached that of glycogen, 0.85 , the ratio in glycogen throughout its formation. Since glucuronide was deposited in the rat with an 0.36 ratio before giving the glucose load, with glucuronide formation of ratio 0.85 , the glucuronide mix would have to approach that of glycogen only with time, as the glucuronide pool turned over. The absolute specific activities of the glycogen deposited as well as the glucuronide formed, decreased with time since the specific activities of the glucose from which they were made decreased. Since Hellerstein et al. (36) express the specific activities of the glycogen from the beginning of deposition to killing of the rat, relative to the specific activities in the blood glucose at the time of killing, the relative specific activities plotted at a given content of glycogen at killing are higher than the actual relative specific activities of the glycogen being deposited at the time of killing. On the other hand, glucuronide specific activities represent those in glucuronide formed in $30 \mathrm{~min}$ to $2 \mathrm{~h}$ before killing. This is the major reason why the comparisons of Hellerstein et al. show relatively higher ${ }^{3} \mathrm{H}$ specific activities of glycogen than the glucuronide after several hours of glycogen deposition and why the ${ }^{14} \mathrm{C}$ specific activities of glycogen appear to approach that of the glucuronide more rapidly than for the ${ }^{3} \mathrm{H}$ specific activities. The higher absolute specific activities of the glucuronide made in preload period provide the major reason for the ${ }^{3} \mathrm{H} /{ }^{14} \mathrm{C}$ ratios rising relatively slowly toward 0.85 .

\section{References}

1. Scofield, R. F., K. Kosugi, V. Chandramouli, K. Kumaran, W. C. Schumann, and B. R. Landau. 1985. The nature of the pentose pathway in liver. J. Biol. Chem. 260:15439-15444.

2. Packham, M. A., and G. C. Butler. 1952. Studies of the biological synthesis of glucuronides. J. Biol. Chem. 194:349-357.

3. Abraham, S., and W. Z. Hassid. 1957. The synthesis and degradation of isotopically labeled carbohydrates and carbohydrate intermediates. In Methods in Enzymology. S. P. Colowick and N. O. Kaplan, editors. Vol. IV. Academic Press, New York. 557-560.

4. Dutton, G. J. 1980. Glucuronidation of Drugs and Other Compounds. CRC Press, Inc., Boca Raton, FL. 149-158.

5. Tocco, D. J., G. O. Breault, A. G. Zacchei, S. L. Steelman, and C. V. Perrier. 1975. Physiological disposition and metabolism of 5-(2',4'-difluorophenyl)salicylic acid, a new salicylate. Drug Metab. Dispos. 3:453-466.

6. Musson, D. G., J. H. Lin, K. A. Lyon, D. J. Tocco, and K. C. Yeh. 1985. Assay methodology for quantification of the ester and ether glucuronide conjugates of diflunisal in human urine. J. Chromatogr. 337:363-378.

7. Katz, J., and J. D. McGarry. 1984. The glucose paradox. Is glucose a substrate for liver metabolism? J. Clin. Invest. 74:1901-1909.

8. Newgard, C. B., L. J. Hirsch, D. W. Foster, and J. D. McGarry. 1983. Studies on the mechanism by which exogenous glucose is converted into liver glycogen in the rat. J. Biol. Chem. 258:8046-8052.

9. Newgard, C. B., S. V. Moore, D. W. Foster, and J. D. McGarry. 1984. Efficient hepatic glycogen synthesis in refeeding rats requires continued carbon flow through the gluconeogenic pathway. J. Biol. Chem. 259:6958-6963.

10. Scofield, R. F., K. Kosugi, W. C. Schumann, K. Kumaran, and B. R. Landau. 1985. Quantitative estimation of the pathways followed in the conversion to glycogen of glucose administered to the fasted rat. J. Biol. Chem. 260:8777-8782.

11. Shulman, G. I., D. L. Rothman, D. Smith, C. M. Johnson, J. B. Blair, R. G. Shulman, and R. A. DeFronzo. 1985. Mechanism of liver glycogen repletion in vivo by nuclear magnetic resonance spectroscopy. J. Clin. Invest. 76:1229-1236.

12. Kuwajima, M., S. Golden, J. Katz, R. H. Unger, D. W. Foster, and J. D. McGarry. 1986. Active hepatic glycogen synthesis from gluconeogenic precursors despite high tissue levels of fructose 2,6-bisphosphate. J. Biol. Chem. 261:2632-2637.

13. Shulman, G., L. Rossetti, D. Rothman, J. Blair, and D. Smith. 1986. Quantitation of gluconeogenic precursors in glycogen synthesis using nuclear magnetic resonance (NMR). Diabetes. 35:38A.

14. Kalderon, B., A. Gopher, and A. Lapidot. 1986. Metabolic pathways leading to liver glycogen repletion in vivo, studied by GC-MS and NMR. FEBS (Fed. Eur. Biochem. Soc.) Lett. 204:29-32.

15. Radziuk, J. 1982. Sources of carbon in hepatic glycogen synthesis during absorption of an oral glucose load in humans. Fed. Proc. 41:110-116.

16. Wentz, F. E., A. D. Marcy, and M. J. Gray. 1982. Analysis of wood sugars in pulp and paper industry samples by HPLC. J. Chromatogr. Sci. 20:349-352.

17. Kadish, A. H., R. L. Litle, and J. C. Sternberg. 1968. A new and rapid method for the determination of glucose by measurement of rate of oxygen consumption. Clin. Chem. 14:116-131.

18. Somogyi, M. 1950. Determination of blood sugar. J. Biol. Chem. 160:69-73.

19. Partridge, S. M., and R. G. Westall. 1948. Filter-paper partition chromatography of sugars. I. General description and application to the qualitative analysis of sugars in apple juice, egg white and fetal blood of sheep. Biochem. J. 42:238-250.

20. Smith, F., and A. M. Stephen. 1960. Diborane reduction of carboxyl groups in carbohydrates. Tetrahed. Lett. 7:17-23.

21. Khym, J. X., and D. G. Doherty. 1952. The separation of sugars by ion exchange. J. Am. Chem. Soc. 74:3199-3200.

22. Dische, Z. 1950. A modification of the carbazole reaction of 
hexuronic acids for the study of polyuronides. J. Biol. Chem. 183:489-494.

23. Hostetler, K. Y., H. R. Williams, W. W. Shreeve, and B. R. Landau. 1969. Conversion of specifically ${ }^{14} \mathrm{C}$-labeled lactate and pyruvate to glucose in man. J. Biol. Chem. 244:2075-2077.

24. Reichard, G. A., Jr., N. F. Moury, Jr., N. J. Hochella, A. L. Patterson, and S. Weinhouse. 1963. Quantitative estimation of the Cori cycle in the human. J. Biol. Chem. 238:495-501.

25. Katz, J. 1985. Determination of gluconeogenesis in vivo with ${ }^{14} \mathrm{C}$-labeled substrates. Am. J. Physiol. 248:R391-R399.

26. Radziuk, J. 1981. Glucose and glycogen metabolism following glucose ingestion in man. A turnover approach. In Carbohydrate Metabolism, C. Corbelli, and R. N. Bergman, editors. John Wiley and Sons, New York. 239-266.

27. Ferrannini, E., O. Björkman, G. A. Reichard, Jr., A. Pilo, M. Olsson, J. Wahren, and R. A. DeFronzo. 1985. The disposal of an oral glucose load in healthy subjects. A quantitative study. Diabetes. 34:580-588.

28. Firth, R. G., P. M. Bell, H. M. Marsh, I. Hansen, and R. A Rizza. 1986. Postprandial hyperglycemia in patients with non-insulin dependent diabetes mellitus. J. Clin. Invest. 77:1525-1532.

29. Baker, N. 1977. Measurement of glucose recycling and liver glycogen synthesis in mice using doubly labeled substrates. Fed. Proc. 36:253-258.

30. Felig, P., J. Wahren, and R. Hendler. 1975. Influence of oral glucose ingestion on splanchnic glucose and gluconeogenic substrate metabolism in man. Diabetes. 24:468-475.
31. Wahren, J., O. Björkman, B. Nyberg, L. Thulin, and L. S. Eriksson. 1984. Are dietary carbohydrates converted to three-carbon compounds in the human gastrointestinal tract? Clin. Nutr. 4:051. (Abstr.)

32. Pang, K. S., and J. R. Gillette. 1978. Complications in the estimation of hepatic blood flow by pharmacokinetic parameters. Drug Metab. Dispos. 6:567-576.

33. Hart, S., I. Calder, B. Ross, and J. Tange. 1980. Renal metabolism of paracetamol. Studies in the isolated perfused rat kidney. Clin. Sci. 58:379-384.

34. Galinsky, R. E., and G. Levy. 1981. Dose- and time-dependent elimination of acetaminophen in rats: Pharmacokinetic implications of cosubstrate depletion. J. Pharmacol. Exp. Ther. 210:14-20.

35. Lowenthal, D. T., S. Oie, J. C. Van Stone, W. A. Briggs, and G. Levy. 1976. Pharmacokinetics of acetaminophen elimination by anephric patients. J. Pharmacol. Exp. Ther. 196:570-578.

36. Hellerstein, M. K., D. J. Greenbatt, and H. N. Munro. 1986. Glycoconjugates as noninvasive probes of intrahepatic metabolism: Pathways of glucose entry into compartmentalized hepatic UDP-glucose pools during glycogen accumulation. Proc. Natl. Acad. Sci. USA. 83:7044-7048.

37. Watari, N., M. Hanawa, M. Iwai, and N. Kaneniwa. 1984. Pharmacokinetic study of the enterohepatic circulation of acetaminophen glucuronide in rats. J. Pharm. Dyn. 7:811-819.

38. Watari, N., M. Iwai, and N. Kaneniwa. 1983. Pharmacokinetic study of the fate of acetaminophen and its conjugates in rats. J. Pharmacokin. Biopharm. 11:245-272. 